\title{
Hepatitis A among workers from a waste water treatment plant during a small community outbreak
}

\author{
Gaston De Serres, Denis Laliberté
}

\begin{abstract}
Objective-This is a case report describing the occurrence of hepatitis $A$ in three workers at a waste water treatment plant during a small community outbreak involving 16 cases.

Case report-The first case was a 26 year old operator who had worked in the plant for two years, the second was a 23 year old employee hired to add new biolite in the secondary treatment area. These two cases never worked together and only met two or three times before the onset of disease in the second case. The third case occured three months later in a 34 year old ventilation mechanic. All three cases were confirmed by IgM serology and virus was recovered by polymerase chain reaction in the stools of the last two cases. Despite an extensive search for other risk factors for hepatitis $A$ in these workers none was found.

Conclusion-This report confirms that hepatitis $A$ is an occupational hazard for sewage workers. The numerous potential sources of contamination associated with that occupation support the use of vaccine to provide effective prevention.
\end{abstract}

(Occup Environ Med 1997;54:60-62)

Keywords: hepatitis A; sewage workers; waste water

Currently, the Centre for Disease Control does not recommend hepatitis $A$ vaccination for waste water workers in the United States ${ }^{1}$ and, in Canada, the National Advisory Committee on Immunisation (NACI) considers that the need for vaccination is uncertain because "Sewerage workers have not been shown to be at increased risk in Canada". ${ }^{2}$

Between June and September 1995, 16 serologically confirmed cases of hepatitis A linked to a contaminated well were reported in the Quebec city area. Most cases lived on a nearby island in which sludge from the septic tanks of the houses were treated in the Quebec city waste water treatment plant. Moreover, most of the cases worked or often went to Quebec city where they used the sanitary installations. This paper describes the occurrence of three cases of hepatitis A among workers at the waste water treatment plant during this small community outbreak and the results of the ensuing investigation.

\section{Setting}

This waste water treatment plant was opened in 1991 and all installations are indoor. It includes primary treatment by decantation and secondary treatment by biofiltration. During biofiltration, water is filtered through biolite, an argilous tiny gravel. The plant processes an average of $10000 \mathrm{~m}^{3}$ of used water an hour with peaks of $30000 \mathrm{~m}^{3}$. Protective clothes and devices (rubber clothes and boots, latex gloves, and paper mask) are available but not often used. The dining area is located outside the process rooms and although workers wash their hands, they do not change their clothes before eating. In this plant there were at least three possible main sources of contamination: the splashes (either small or large) by waste water and sludge, the aerosols, and the hand contamination. Operators and mechanics were exposed to all three sources, whereas electricians, foremen, and inspecting staff were less likely to be splashed and laboratory, warehouse, and office staff were not exposed to splashes and had low exposure to aerosols because they spent most of their time outside the process rooms. The splashes occur either when water samples are collected or when equipment is maintained or cleaned with a hose and water.

\section{Case report}

All three cases were questioned directly by both authors. The first case was a 26 year old operator who had worked in the plant for two years. His first symptoms occurred on 9 August and hepatitis A was confirmed by IgM serology. The second case was a 23 year old employee hired in July 95 to add new biolite in the secondary treatment area. He was thus mainly working with uncontaminated material but all his time was spent in the biofiltration room where aerosols are abundant. $\mathrm{He}$ became sick on 9 September and hepatitis A was confirmed both by $\operatorname{IgM}$ serology and recovery of the virus from the stools by polymerase chain reaction. ${ }^{3}$ These two cases never worked together and had only met two or 
Proportion of workers immune to hepatitis $A$ according to age and type of occupation

\begin{tabular}{llll}
\hline & $\begin{array}{l}\text { Operators and } \\
\text { mechanics } \\
n(\%)\end{array}$ & $\begin{array}{l}\text { Other workers } \\
n(\%)\end{array}$ & $\begin{array}{l}\text { Total } \\
n(\%)\end{array}$ \\
\hline $25-34$ & $2 / 24(8)$ & $1 / 15(7)$ & $3 / 39(8)$ \\
$35-44$ & $7 / 19(37)$ & $5 / 17(29)$ & $12 / 36(33)$ \\
245 & $2 / 4(50)$ & $4 / 6(67)$ & $6 / 10(60)$ \\
Total & $11 / 47(23)$ & $10 / 38(26)$ & $21 / 85(25)$ \\
\hline
\end{tabular}

three times before the onset of disease in the second case. The third case was a 34 year old ventilation mechanic who received a first dose of hepatitis A vaccine on 12 December. He felt exhausted on the 21 December, and became icteric on 4 January. Hepatitis A was confirmed by IgM and the virus was also found in the stools. The virus found in both workers was sequenced and was identical to those recovered in the cases from the island.

All these workers had stable monogamous heterosexual relations, reported no homosexual behaviour, had not been in contact with a known case of hepatitis $\mathrm{A}$, did not use injectable drugs, had not had a blood transfusion, had not eaten shellfish, had not travelled to areas where hepatitis $A$ is endemic, and had not gone to the island affected by the hepatitis A outbreak. The three workers bought their food in different places in the city and no common food supplier was found.

\section{INTERVENTION AND FURTHER INVESTIGATION}

After the onset of the first two cases in the plant, vaccine was offered to all workers who were seronegative to hepatitis A. Serum samples were tested with IM HAVAB microparticle enzyme immunoassay (Abbott Laboratories, Abbott Park, Il). Workers completed a self administered questionnaire which evaluated the frequency of splashes with waste water or sludge, age, educational level, time of employment at the plant, type of job, and history of jaundice.

\section{Results}

The mean (SD) age of the other workers at the plant was 36 (7) years and $87 \%$ were men. During the four weeks before the survey, $79 \%$ of the operators and mechanics received small splashes in comparison with $20 \%$ for other workers. A total of $19 \%$ of the operators and mechanics and none of the other workers received large splashes ( $<125 \mathrm{ml}$ of contaminated water).

All workers (85) agreed to have their blood tested for immunity against hepatitis A except one operator who had already received a first dose of vaccine: $21(25 \%)$ had IgG but none had IgM. No one reported a history of jaundice. The proportion of IgG positive workers increased with age but was similar whatever their type of occupation (table).

\section{Discussion}

Seroprevalence studies ${ }^{45}$ and reports of outbreaks ${ }^{6}$ had suggested that hepatitis $A$ was a risk for sewage workers but these studies lacked either data on incidence or control of confounders. This report had shown four interesting facts. Firstly, associated with a small community outbreak, three workers from the waste water treament plant had confirmed hepatitis A but had no risk factor for the disease apart from their occupation. Transmission between workers is very unlikely and no subacute or asymptomatic hepatitis A occurred in other workers as shown by negative IgM serology. Secondly, the prevaccination prevalence of antibody to hepatitis A virus was low among all workers $(21 \%)$ and very low among workers younger than 35 years $(8 \%)$. This confirms the high level of susceptibility to hepatitis $A$ in young workers and is consistent with the general epidemiology of hepatitis A in most developed countries where infection at a young age is now infrequent. Thirdly, a community outbreak can be a source of exposure for a population of susceptible workers. This hypothesis is also supported by a similar epidemic in workers from Kansas city (G Hoff, personal communication). However, the size of the community outbreak in Kansas was much greater than it was here. Fourthly, it is difficult to identify exactly how, where, and when our cases were infected in the plant as contamination can occur from aerosols, small and large splashes, and workers' hands. Although inhalation of aerosols can be avoided by a mask adapted to the high humidity of the plant and exposure from splashes when operating hoses can be prevented by rubber clothes and a face shield, it seems difficult to control every source of exposure; moreover, hand washing is probably not as efficient as it should be because workers recontaminate their hands after turning off taps, opening the door to leave the area of work, touching their clothes, transporting their tools, etc.

All these facts question the current recommandations about hepatitis A vaccine for sewage workers and support the conclusion of a previous study conducted in Quebec city among sewer workers stating that "the decision to vaccinate sewer workers against hepatitis A should take into account that it is impossible to avoid all contact with sewage fluid and despite the fact that the actual incidence of hepatitis $A$ is low, there is a real possibility of sporadic exposure during a future outbreak". ${ }^{7}$ This case report confirms that hepatitis $A$ is an occupational hazard for sewage workers. Fortunately, this hazard is now preventable by vaccination.

We acknowledge Lise Desjardins, Micheline Giroux, Danielle Fauchon, Lorraine Simoneau, Sally Brylon, and Danielle Le Henaff who did the intervention at the plant. We are indebted to Robert Gervais, Marc Dionne, and Bernard Duval who revised this manuscript and to Theresa Cromeans and Harold Margolis for the polymerase chain reaction tests and virus sequencing.

1 CDC. Hepatitis A vaccine: recommendations from the Advisory Committee on Immunization Pratice (ACIP) Morb Mortal Wkly Rep 1997;47:(in press).

2 National Advisory Committee on Immunization. Statement on the prevention of hepatitis A infections. Can Commun Dis Rep 1994;20:133-43.

3 Cromeans TL, Nainan OV, Margolis HS. Detection of hepatitis $A$ virus in oyster meat by nucleic acid amplification. hepatitis $A$ virus in oyster meat by nucleic acid amplification. Viral Hepatitis and Liver Disease. Rome: 1996. 
4 Skinhoj P, Hollinger FB, Hovind-Hougen K, Lous P. Infectious liver diseases in three groups of Copenhagen workers: correlation of hepatitis $\mathrm{A}$ infection to sewage exposure. Arch Environ Health 1981;36:139-43.

5 Heng BH, Goh KT, Doraisingham S, Quek GH. Prevalence of hepatitis A virus infection among sewage workers in Singapore. Epidemiol Infect 1994;113:121-8.
6 Timothy EM, Mephan P. Outbreak of infective hepatitis amongst sewage sludige spreaders. Communicable Disease Repori CDR Rev 1984;3:3.

7 De Serres G, Levesque B, Higrins R, Major M, Laliberte $D$, Boulianne $N$, et al. Need for vaccination of sewer worker against leptospirosis and hepatitis A. Occup Worker against leptospirosis

\section{Rejected manuscripts}

From February 1994, authors whose submitted articles are rejected will be advised of the decision and one copy of the article, together with any reviewers' comments, will be returned to them. The fournal will destroy remaining copies of the article but correspondence and reviewers' comments will be kept. 